\title{
The Assumption of SELF-Responsibility FOR Health Behaviour Change in Patients With HYPERTENSION FROM POOR SOCIO-ECONOMIC AREAS
}

\author{
ABSTRACT: Patients with hypertension need to convert their knowledge \\ about the disease and its management into meaningful action to be able to \\ change their health behaviour. By doing this they are able to reduce the risk \\ of the cardiovascular complications that are associated with hypertension. \\ If they can change their health behaviour it can be said that they have \\ taken responsibility for their health. In this study a group of patients with \\ hypertension who assumed responsibility for health behaviour change \\ STEWART AV, M Sc (Physiotherapy)'; \\ EALES CJ, PhD'; \\ DAVIES KA, B Sc (Physiotherapy) $)^{1}$ \\ ${ }^{1}$ Physiotherapy Department, Faculty of Health \\ Sciences, University of the Witwatersrand. \\ during a health behaviour modification programme was identified and \\ compared to a group who did not. There were significant differences between the group that assumed responsibility \\ for health behaviour change and the group that did not. The group that assumed responsibility: \\ - had the support of a health care practitioner and a family member ( $p<0,000)$; \\ - were employed ( $p=0.03)$; \\ - were not anxious or depressed $(p=0.07)$; \\ - experienced their usual sex-lives ( $p=0.03)$; \\ - did not have symptoms of heart pounding present ( $p=0.03$ ). \\ The adjusted odds ratio obtained from a logistic regression analysis showed a seven- times more likelihood of \\ patients becoming responsible for their health if they were supported by their families and a health-care practitioner.
}

\section{KEY WORDS: SELF-RESPONSIBILITY, HEALTH BEHAVIOUR MODIFICATION, HYPERTENSION}

\section{INTRODUCTION}

A lack of knowledge of hypertension and how to manage it, is probably the most important barrier to patients being able to make health behaviour changes (Prochaska et al, 1992). Once patients with hypertension have some knowledge of the disease, its pathology; associated risk factors; consequences of the disease if not managed and how to modify their health behaviour, what they subsequently do with the knowledge is of interest. If they can convert the gained knowledge into meaningful action to change health behaviour, it can be argued that patients have taken responsibility for their own health.

For effective health behaviour change in hypertension, patients have to embark on a process of self-care. Self-care is the active participation of patients in a collaborative partnership with healthcare practitioners to improve their health (Stoller et al, 1993). The interaction between patients and health-care practitioners should be such that patients increasingly take positive action for their health (DeFriese et al,1994). In order for patients to improve their state of health, they must have the knowledge of what to do. In other words self-care implies responsible behaviour towards the attainment of optimal health.

A more comprehensive concept than self-care is the concept of self-responsibility. Patients should take responsibility for their health (Ginsberg, 1977). Knowles, (1977) has suggested that the right to health be replaced by a moral obligation to preserve one's own health. Patients then have the right to information, accessible good quality medical services and minimal financial barriers.

Thus the term self-responsibility may well be a more appropriate term to describe actions required to improve health (Eales and Stewart, 2001). Selfresponsibility implies knowing and taking correct actions to improve health. This sense of self-responsibility may be the best predictor for the reduction of disability and handicap in chronic disease (Oldridge, 1986). For patients to become responsible both they and their families should be provided with information about disease and its management (Wallston and Wallston, 1978). This responsibility for one's own health can be defined thus -"self-responsibility is the necessary action for an optimal health outcome and can be defined as the moral duty of the patient to successfully execute the required health behaviour for improved health" (Eales and Stewart, 2001).

In this study the ability of patients with hypertension to be self-responsible during a health behaviour modification programme was tested. To test this ability patients who had undergone a programme of health behaviour modification

\section{CORRESPONDENCE TO:}

\section{A Stewart}

Physiotherapy Department Faculty of Health Sciences University of the Witwatersrand

7 York Road, Parktown 2193

Tel: (011) 717-2064

Fax: (011) 643-4318 
were selected into a "Best Performers" group and compared to the rest of the sample of patients in the programme.

It was felt that strict criteria should be imposed when selecting the "Best Performers" group. This was because knowledge gained in such an intervention needs to be translated into measurable outcomes of health behaviour change in order for a health behaviour modification programme to be considered effective (Glanz et al, 1997). The criteria used to select this group were that patients had to have improvements in the two measurable outcomes in the study namely, exercise capacity and weight.

By using these criteria for best performers it can be argued that patients' self-responsibility was tested. Considerable changes had to be made to their health behaviour in order for patients to demonstrate changes in these two measurable outcomes (Sotile, 1996). Patients had to change from a sedentary life-style to one where they exercised. In addition they had to markedly modify their diet.

The aim of this study was thus to identify the specific characteristics of patients who had assumed responsibility for their health.

\section{METHOD}

Permission to do this study was obtained from the committee for research on human subjects at the University of the Witwatersrand. The ethical clearance number is M970624. All patients signed a consent form after having had the study explained to them.

Patients in this study had previously been part of a 24-week programme to modify health behaviour. They all attended a hypertension clinic at a tertiary care hospital in Johannesburg. They had been randomly assigned to either an Experimental or Control group.

Both groups were given a home based exercise programme and had a once a month educational intervention. The intervention consisted of four, once a month educational sessions during which time the pathology of hypertension, cardiovascular risk factor modification and medication were discussed.

In addition the Experimental group had a once a month telephonic intervention to both patients and a member of the patients' family. During the telephonic intervention patients were encouraged in their efforts to reduce cardiovascular risk factors; their exercise programmes were checked and important points in the previous educational session were re-emphasised. The member of the patients' family who was telephoned was educated about hypertension and was encouraged to be supportive.

At the conclusion of the 24-week intervention some patients were identified as "Best Performers" and then compared to the rest of the whole sample of patients who had participated in this study. The "Best Performers" were those patients who had both lost weight and walked at least a further 20 metres during the six minute walk test (Guyatt et al, 1985).

Fisher's exact test was undertaken to identify differences between the "Best Performers" group and the remainder of the sample. The factors tested were, basic demographic data, presence of risk factors, presence of symptoms, perceived feelings of well-being, and the group to which patients were assigned at the start of the study. Once these factors were identified a logistic regression analysis was undertaken. Adjusted odds ratios and their $95 \%$ confidence intervals were then obtained from the logistic regression analysis.

\section{RESULTS AND DISCUSSION}

There were 19 patients in the Best Performers group. Of the 19 patients in the Best Performers group 15 were originally in the Experimental group and 4 in the Control group. There were 64 patients in the remainder of the sample.

\section{Table 1: Baseline Data}

\begin{tabular}{|l|l|l|l|}
\hline & $\begin{array}{l}\text { Best performers } \\
\text { Group } \mathbf{n = 1 9}\end{array}$ & $\begin{array}{l}\text { Rest of sa mple } \\
\mathbf{n = 6 4}\end{array}$ & p value \\
\hline Knowledge \% & $49( \pm 14)$ & $50( \pm 15)$ & $p=0.58$ \\
\hline Weight $\mathrm{kg}$ & $84( \pm 20)$ & $78( \pm 18)$ & $p=0.23$ \\
\hline Distance Walked $\mathrm{m}$ & $434( \pm 71)$ & $455( \pm 103)$ & $\mathrm{p}=0.41$ \\
\hline
\end{tabular}

Table 2: Change in distance walked and weight after 24 weeks

\begin{tabular}{|l|l|}
\hline Difference between week $\mathbf{2 4}$ and week $\mathbf{0}$ & Best performers group $(\mathbf{n}=\mathbf{1 9})$ \\
\hline$\Delta$ Distance $\mathrm{m}$ & $64( \pm 49)$ \\
\hline$\Delta$ W eight $\mathrm{kg}$ & $-3( \pm 1)$ \\
\hline
\end{tabular}

The baseline data of this group (measured at the start of the study) is shown in Table 1.

There were no significantly differences in the baseline data between the two groups.

After 24 weeks the percentage knowledge score in the "Best Performers" group was $76( \pm 21) \%$. This was a percentage change of $29 \%$, indicative of the fact that this group of patients probably had the necessary knowledge to change their health behaviour.

The changes in distance walked and weight of the "Best Performers" group are shown in Table 2.

The "Best Performers" group increased the distance walked in the exercise test by a mean of 64 metres and they had a mean drop in weight of $-3 \mathrm{Kgs}$.

The following data obtained at the initial assessment namely; demographic; risk factors, presence of symptoms and general measures of perceived well being, were compared between the "Best Performers" group and the rest of the sample. In addition the percentage of patients in the "Best Performers" group who were in either the Experimental or Control groups was compared to the percentage of patients in the rest of the sample who were in either the Experimental or Control groups.

Some significant differences between the "Best Performers" group and the rest of the sample emerged as a result of this comparison. The following significant differences between these two groups were subsequently identified in the logistic regression analysis as factors affecting performance. These were, 
- the group patients were in, either Experimental or Control $(\mathrm{p}<0.000)$

- if they were employed $(\mathrm{p}=0.03)$

- if they were anxious and depressed (0.07)

- if they were experiencing their usual sex-life (0.03)

- if they felt that their hearts were pounding in their chests $(p=0.03)$

The adjusted odds ratios and their 95\% confidence intervals were obtained from the logistic regression analysis of

The majority of patients in the Best Performers group were in the Experimental group, a total of 15 of the 19 patients. The Experimental group had the supportive triad of themselves, a member of their family and the healthcare practitioner. Within this emotionally supportive environment they were able to gain sufficient knowledge to act as a basis for health behaviour change (Sotile, 1996).

The major goal of health behaviour modification programmes is to "instill and strengthen patients' belief in treatment effectiveness and their own ability to effect change" (O'Leary in Sotile, 1996). In this study the multiple interventions provided in the Experimental group by the support of the family, the health-care practitioner and the educational sessions provided the support and skills training necessary to change this groups' exercise and dietary habits. The increased knowledge possibly led to a greater understanding of what risk factor modification tries to achieve. This greater understanding may have led to greater belief in the effectiveness of risk factor the above factors.

modification leading to the improvements in management of risk factors seen above.

As a result of being in the Experimental group the chance of a good outcome was 7 times increased as opposed to being in the Control group. The additional support that was provided by the intervention in the Experimental group appears to have increased patients' ability to be self-responsible. These patients' belief in their own ability to effect change based on their belief of the treatment effect was enhanced by being in this group (Sotile, 1996). This illustrates the power of an intervention that provides support and is inclusive of patients, families and health care practitioners.

If patients were employed they were likely to have the above good outcome, namely increased exercise capacity and a reduction in weight. The patients in this study came from socio-economic areas where there are high levels of unemployment with resultant high levels of anxiety and depression

Work productivity is one of the domains of quality of life suggested by Ory (1994). Being employed is thus a domain that contributes to a better quality of life. Employment possibly leads to greater feelings of self worth and belief in one's own ability to take charge of one's life. This is then seen in the ability of patients to accept responsibility for changing their health behaviour.

If patients were not anxious and depressed they were likely to have a good outcome in this study. Depression and anxiety have a negative impact on patients' ability to adhere to health

Table 3: Adjusted odds ratios and $95 \%$ confidence intervals

\begin{tabular}{|c|c|c|c|c|c|}
\hline 0 utcome & $\begin{array}{l}\text { Odds } \\
\text { Ratio }\end{array}$ & Std Err & $\mathbf{Z}$ & $p>|z|$ & $\begin{array}{l}95 \% \\
\text { confidence } \\
\text { interval }\end{array}$ \\
\hline Group (E) & 7.120 & 5.063 & 2.760 & 0.006 & $\begin{array}{l}1.766 \\
28.698\end{array}$ \\
\hline Employment (No) & 0.352 & 0.248 & -1.484 & 0.138 & $\begin{array}{l}0.089 \\
1.397\end{array}$ \\
\hline $\begin{array}{l}\text { Anxiety } \\
\text { Depression (Yes) }\end{array}$ & 0.354 & 0.239 & -1.536 & 0.124 & $\begin{array}{l}0.094 \\
1.331\end{array}$ \\
\hline Sex-life (N o) & 0.367 & 0.246 & -1.494 & 0.135 & $\begin{array}{l}0.0983 \\
1.367\end{array}$ \\
\hline $\begin{array}{l}\text { Sensation of heart } \\
\text { pounding (Yes) }\end{array}$ & 0.205 & 0.140 & -2.324 & 0.020 & $\begin{array}{l}0.054 \\
0.780\end{array}$ \\
\hline
\end{tabular}

behaviour modification (Campbell, 1970). Patients in a supportive environment as provided by this study have an outlet for their anxieties.

Patients in the "Best Performers "group were experiencing their usual sex-lives. This could mean that they were in a supportive relationship that made them confident enough to embark on a health behaviour modification programme.

If patients had sensations of heart pounding at the start of the programme they were unlikely to have a good outcome as judged by the criteria in this study. It is possible that patients who experienced this symptom did not feel confident about exercise and may in fact have been anxious about exercising. As a result their exercise effort was probably not sufficient to make a change in exercise capacity.

There are some similarities between these patients and post cardiac surgery patients described by Eales et al, (1998). Eales' group were knowledgeable, had a reasonable income, were educated, were supported by their spouses and were satisfied with the outcome of their cardiac surgery. The patients in the "Best Performers" group, had family support, and experienced their usual sex lives. They were employed implying a steady income. Patients were neither anxious nor depressed which may mean acceptance of their situation.

The concept of self-responsibility is increasingly important in rehabilitation and in the management of chronic disease (Oldridge, 1986; Eales and Stewart, 2001). Patients need to become morally accountable for their actions in regard to their health. For any intervention to be considered successful patients need to become self-responsible. In order for patients to become self-responsible they need the support of an integrated team consisting of themselves, their families and a health-care practitioner (Wallston and Wallston, 1978). In the Experimental group patients became part of such a team by way of the triad between patient, family member and health-care practitioner. In addition to their knowledge being increased, patients were able to make attempts at changing their life styles within the supportive environment provided by the triad. 
The "Best Performers" group can be considered to be self-responsible. The increased knowledge gained by the group was used to change a life-time of habits. The group was from a sedentary background and was obese. They changed their habits sufficiently to increase their exercise capacity and to reduce their weight. They were able to do this with the support and individual attention given by the health-care practitioner and a member of their family. The involvement of the family in the management of long-term chronic disease is becoming of increasing importance. Sotile,(1996) talks about collaborative family health care as becoming the norm in the management of all medical patients. In addition it needs to be realised by healthcare practitioners that patients seek help from health-care practitioners on many levels, an emotional level, advice with family concerns, their worries and they need positive support from health-care practitioners when they are doing well (Sotile,1996).

\section{CONCLUSION}

The most important conclusion of this study is that the support of the triad of health care practitioner, patient and family member facilitates the development of self-responsibility. This has important clinical implications and supports the concept of holistic management of patients.

Patients who were able to increase their exercise capacity and lose weight were considered to be self-responsible in this study.

The patients who were self-responsible were employed; were not anxious or depressed; were experiencing their usual sex-lives and did not have sensations of heart pounding.

\section{REFERENCES}

Campbell A 1970 Subjective measures of wellbeing American Psychologist 31: 117-124

DeFriese G H Konrad TR Woomert A Norburn JEK Bernard S 1994 Self-care and quality of life in old age In Abeles RP Gift HC Ory MG (eds) Ageing and quality of life 99-117

Eales C Stewart A Noakes T Goodman M 1998 Successful Rehabilitation in Patients' with Chronic Disease. The South African Journal of Physiotherapy 54 (2) 6-9

Eales C J and Stewart A V 2001 Health and Responsibility Self-efficacy, Self-care and Self-responsibility South African Journal of Physiotherapy 57 (1): 20-25

Ginsberg E 1977 The sacred cows of health manpower Man and Medicine 2: 235-242

Glanz K Lewis F Rimer B 1997 Health Behaviour and Health Education theory research and practice 2nd Edition Jossy Bass Inc Publishers California

Guyatt GH Sullivan MJ Thompson PJ Fallen EL Pugsley SO Taylor DW Berman L B 1985 The six minute walk: A new measure of exercise capacity in patients with chronic heart failure Canadian Medical Association Journal 132: 919-923
Knowles JH 1977 Responsibility for heallth Science198:4322 (editorial)

Oldridge NB 1986 Cardiac Rehabilitation, Self-Responsibility and Quality of Life Journal of Cardiopulmonary Rehabilitation 6: 53-156

Ory MG Cox DM Gift HC Abeles RP 1994 Aging and quality of life: Celebrating new research discoveries in Abeles RP Gift HC Ory MG eds Ageing and Quality of life Springer Publishing Company Inc Broadway New York

Prochaska JO DIClemente CC Norcross JC 1992 In search of how people change: Applications to addictive behaviour American Psychologist 47(9) 1102-1114

Sotile WM 1996 Psycho-social Interventions for Cardiopulmonary Patients-a guide for health professionals. Human Kinetics Champaign Illinois

Stoller EP Forsyer LE Portugal S 1993 Selfcare responses to symptoms by older persons: a health diary study of illness behaviour Medical Care 31: 24-42

Wallston KA Wallston BS 1978 Locus of Control of Health A Review of the Literature Health Education Monographs 6 (2) 107-117 


\title{
EXERCISE TOLERANCE IN TyPe - 2 Male Diabetics
}

\begin{abstract}
The objective of this study was to compare the exercise tolerance of a set of male diabetic Nigerians with non-diabetic male subjects. Ten male Type-2 diabetics between the ages of 35 and 50 years in good glycaemic control and ten male non-diabetic controls of similar age were exercised on the ergometer at uptake of $90 \%$ and $60 \%$ V02 max respectively for anaerobic and aerobic exercises. Cardiovascular and fatigue rates or times to fatigue were then determined in both groups.

In both diabetics and controls, the time to fatigue was significantly longer

\section{O DEBIYI DO, MSC (PT) ${ }^{1}$, OHWOVORIOLE AE ${ }^{2}$}

${ }^{1}$ Department of Physiotherapy, College of Medicine, University Of Lagos, Nigeria.

2 Department of Medicine, College Of Medicine, University Of Lagos, Nigeria.

during exercise at $60 \% \mathrm{VO}_{2 \max }$ than at $90 \% \mathrm{VO}_{2 \max }(P<0.01)$. During aerobic exercise, the mean times to fatigue were very similar in the diabetic and control men $\{427.5$ (38.0) secs. V 439.0 (56.9) secs. $p>0.1\}$. The diabetic men fatigued more easily than controls under anaerobic condition ( $p 0.1>p>0.05$ ).

Type 2 male diabetics with good glycaemic control appear to tolerate aerobic exercise as well as non-diabetic males, but less so during anaerobic exercise. This difference in aerobic and anaerobic exercise tolerance should be borne in mind in prescribing exercise regimes in patients with type 2 diabetes mellitus.
\end{abstract}

KEY WORDS: TYPE 2 DIABETICS, NIGERIANS, AEROBIC EXERCISE, ANAEROBIC EXERCISE, FATIGUE RATE.

\section{INTRODUCTION}

Physical exercise is helpful in improving the metabolic control of diabetics, especially in those with type 2 diabetes mellitus (DM), in the promotion of good health and the prevention of diabetes mellitus ( Ivy 1997). Before prescribing exercise as a therapeutic and/or preventive measure, it is important to appreciate the likely response of the individual to such an exercise. In patients whose DM is well controlled, exercise may ameliorate the condition further (Larsen et al 1997). On the other hand exercise worsens the metabolic state in diabetics in whom glycaemic control is poor and could precipitate diabetes ketoacidosis in such patients (Perry et al 1993).

The two main forms of DM: Type1 DM and Type $2 \mathrm{DM}$, benefit from exercising but patients with Type $2 \mathrm{DM}$ appear to benefit more (Franz 1997). In clinical practice, type $2 \mathrm{DM}$ accounts for over 90 percent of the diabetic clinic population (Franz 1997). Such patients need to be referred for physical therapy - for adequate and closely monitored exercises. However, there appears to be little or no attention given to this area of study in Nigeria. Therefore, this preliminary report was designed to compare the fatigue states of a group of Type 2 diabetic Nigerians with those of a control group of similar age group, sex, and body size and activity level. The study was also designed to assess the responses of Type 2 diabetic men to aerobic and anaerobic exercises, since these two forms of exercises are the main ones employed in exercise therapy (ADA 1998).

\section{SUBJECTS AND METHODS}

The study was conducted at the College of Medicine of the University of Lagos, Lagos Nigeria. A sample of convenience of ten male Type 2 diabetic patients with good metabolic control (fasting plasma glucose $<120 \mathrm{mg} / \mathrm{dl}$ ), meeting the inclusion criteria was recruited into the study from the Diabetes Clinic of the Lagos University Teaching Hospital. To qualify for inclusion in the study, the persons must have been diagnosed diabetic using standard criteria (WHO 1985), and should be between the ages of 35 and 50 years, and be in good glycaemic control (fasting plasma glucose $<120 \mathrm{mg} / \mathrm{dl}$ ). Informed consent was obtained from each subject and only those who consented were studied. Ethical clearance was obtained from the ethical committee of the Lagos University Teaching
Hospital, Lagos, Nigeria. An invitation was extended until a total of 10 eligible patients had been recruited. All the diabetic subjects were on oral hypoglycaemic agents and had been on treatment for a minimum of two years (i.e. in stable state). Ten healthy subjects of similar age, sex, and body size and activity level and without a personal history of DM acted as controls. They were recruited from the hospital staff.

Both study and control subjects did not have a history of cardiovascular disease, arthritis, smoking or obesity. None of the subjects engaged in regular strenuous competitive exercise.

\section{PROCEDURE}

Each subject was given a pre-exercise review focusing on symptoms and signs of disease affecting the heart and blood vessels, eyes, kidneys and the nervous

\section{CORRESPONDENCE TO: \\ D.O. Odebiyi \\ Department Of Physiotherapy \\ College Of Medicine, \\ University Of Lagos \\ P.M.B. 12003, Lagos, Nigeria \\ e-mail: femiodebiyi@yahoo.com}

